\title{
IUPAC-IUB Commission on Biochemical Nomenclature (CBN)
}

\section{Nomenclature of Iron-Sulfur Proteins}

\author{
1973 Recommendations ${ }^{1}$
}

On August 19, 1967, an informal meeting organized by T. Kimura was held in Tokyo, Japan, to discuss the needs and desires of establishing a systematic nomenclature for the so-called "non-heme iron proteins". The eighteen scientists attending that meeting-all actively investigating the chemistry or biological function of this unique class of proteinsagreed that the time was propitious to stem the proliferation of trivial names that had developed in the last few years, and that the IUPAC-IUB Commission on Biochemical Nomenclature (CBN) be requested to form a subcommittee to establish tentative rules for nomenclature. This recommendation was accepted by CBN at their meeting in Bellagio, Italy, in July 1968 and a subcommission was established ${ }^{2}$.

A formal meeting of the subcommission was held on October 17, 1968, and a provisional system of nomenclature was discussed. Of primary importance was the unanimous agreement that the term "nonheme iron proteins" be abandoned. It was proposed that the general category of iron-containing proteins should have a subdivision composed of "iron-sulfur proteins". Further it was agreed that the terms "ferredoxin" and "rubredoxin" be retained and their usage expanded.

Following this meeting, opinions were obtained by correspondence with members of the subcommission and a meeting of the subcommittee on June 7, 1971, approved the following recommendations.

1 Document of the IUPAC-IUB Commission on Biochemical Nomenclature (CBN), approved by CBN in January 1973, and published by permission of the International Union of Pure and Applied Chemistry and the International Union of Biochemistry.

Comments on and suggestions for future revisions of these Recommendations may be sent to any member of CBN: O. Hoffmann-Ostenhof (chairman), W. E. Cohn (secretary), A. E. Braunstein, B. I. Horecker, P. Kurlson, B. Keil, W. Klyne, C. Liébecq, E. C. Webb, and W. J. Whelen.

Reprints may be obtained from Waldo E. Cohn, Director, NRC Office of Biochemical Nomenclature, Biology Division, Qak Ridge National Laboratory, P.O. Box Y, Oak Ridge, Tennessee, U.S.A. 37830.

2 R. W. Estabrook (convener), T. Kimura, H. Beinert, J. Rabinovitz, A. San Pietro, R. Bartsch, P. Hemmerich, R. Lardy, and E. C. Slater.

\section{RECOMMENDATIONS}

1. Proteins containing iron may be divided into three groups: hemoproteins, iron-sulfur proteins and other iron proteins. The last group includes ferritin, transferrin and the oxygenases. The term "iron-sulfur proteins" refers only to those proteins where the iron is shown to be liganded with inorganic sulfur or cysteine sulfur. When the heme-iron atom in hemoproteins is also liganded with inorganic sulfur or cysteine sulfur, the protein is classified as a hemoprotein.

2. The iron-sulfur proteins may be subdivided into four categories:

2.1. Ferredoxin. This group comprises those ironsulfur proteins with an equal number of iron and labile sulfur atoms, and a negative midpoint redox potential at $\mathrm{pH}$ 7. They are characterized by an EPR (electron-paramagnetic resonance) signal with $\boldsymbol{g}<\mathbf{2}$ for the reduced protein. Ferredoxins are present in plants, animals and bacteria. The source should always be stated. Examples: chloroplast ferredoxin, adrenal ferredoxin (formerly called adrenodoxin), Pseudomonas putida ferredoxin (formerly called putidaredoxin), Clostridium acidi-urici ferredoxin.

Ferredoxin may be abbreviated Fd.

2.2. High-Potential Iron-Sulfur Proteins. Certain microorganisms contain a unique class of iron-sulfur proteins containing acid-labile sulfur, but differing from the ferredoxins in their physical properties. No EPR signal has been detected with the reduced form of this type of protein. The oxidized form is paramagnetic with an EPR signal with a $g$-value of about 2 . At $\mathrm{pH} 7$, the midpoint potential is positive. Until further characterized, the descriptive but cumbersome name "high-potential iron-sulfur protein" should be retained with the source indicated as a prefix, e.g. chromatium high-potential ironsulfur protein.

2.3. Rubredoxins. This group comprises those iron-sulfur proteins without acid-labile sulfur characterized by having iron in a typical mercaptide coordination, i.e. one center surrounded by 4 cysteine 


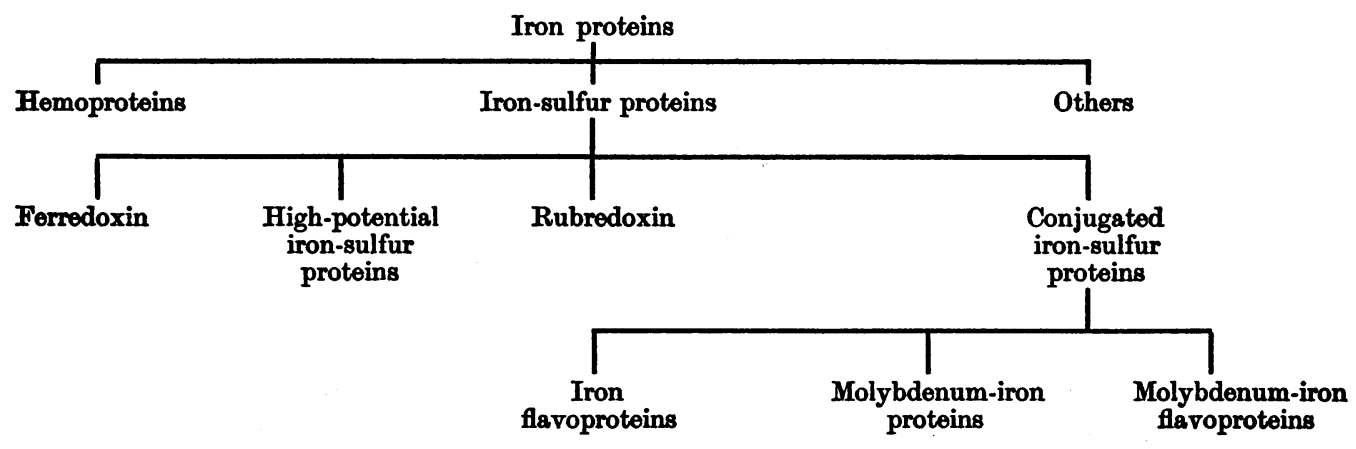

Fig.1. Classification of iron proteins

or equivalent sulfur ligands. Oxidized rubredoxin has a distinctive EPR spectrum with a line at $g=4.3$ whereas the reduced pigment gives no discernible EPR signal. The redox potential for those rubredoxins now characterized are negative at $\mathrm{pH}$ 7.0. The full name should be listed as (source) rubredoxin (function), e.g. Pseudomonas oleovorans rubredoxin, alkane $\omega$-hydroxylation.

2.4. Conjugated Iron-Sulfur Proteins. This group comprises those proteins containing iron and labile sulfur cr iron in a typical mercaptide coordination, but also containing additional prosthetic groups. Many of the iron-containing flavoproteins, molybdenum iron proteins or molybdenum-iron flavoproteins are included. Frequently these proteins may contain, as a component part of the enzyme complex, characteristios (EPR, optical spectra or redox properties) similar to a protein classified in 2.1-2.3. However, since they are now considered in other nomenclature systems, no specific system of naming is now recommended. If desired, a cross-reference to this category of proteins may be included in addition to the present name in order to avoid ambiguity.

The committee has developed the above system of nomenclature fully cognizant that considerably more information will be required before a more definitive nomenclature can be developed. The basis for the above system of nomenclature rests strongly on the chemical properties of the proteins with a number of physical criteria used for further differentiation. It is hoped that the suggested nomenclature is sufficiently flexible to encompass new proteins discovered without the need to generate further trivial names.

The recommended classification is illustrated schematically in Fig. 1.

Acknowledgement. We are indebted to the Editors and Publishers (Springer-Verlag) of the European Journal of Biochemistry for permission to reproduce these Recommendations photographically. 
All Tentative Rules and Proposals of the IUPAC-IUB Commission on Biochemical Nomenclature (CBN) are available from Waldo E. Cohn, Director, NAS-NRC Office of Biochemical Nomenclature, Oak Ridge National Laboratory, P.O. Box Y, Oak Ridge, Tenn. 37830, U.S.A.:

1. Abbreviations and Symbols for Chemical Names of Special Interest in Biological Chemistry [see Biochem. J. (1966) 101, 1-7 (extended by items 6, 11 and 15 below)]

2. Nomenclature of Vitamins, Coenzymes and Related Compounds: Trivial Names of Miscellaneous Compounds of Importance in Biochemistry, Nomenclature of Quinones with Isoprenoid Side Chains, Nomenclature and Symbols for Folic Acid and Related Compounds, Nomenclature of Corrinoids. Tentative Rules [see Biochem. J. (1967) 102, 15-22 (but see item 10 below)].

3. Abbreviated Designation of Amino Acid Derivatives and Peptides [see Biochem.J. (1967) 102, 23-27 (superseded by item 15 below)].

4. Rules for Naming Synthetic Modifications of Natural Peptides [see Biochem. J. (1967) 104, 17-19].

5. The Nomenclature of Lipids. A Document for Discussion [see Biochem. J. (1967) 105, 897-902].

6. Abbreviated Nomenclature of Synthetic Polypeptides (Polymerized Amino Acids) [see Biochem. J. (1968) 106, 577-579 (supeseded by item 18 below)].

7. The Nomenclature of Cyclitols. Tentative Rules [see Biochem. J. (1969) 112, 17-28].

8. A One-Letter Notation for Amino Acid Sequences. Tentative Rules [see Biochem. J. (1969) 113, 1-4].

9. Revised Tentative Rules for Nomenclature of Steroids [see Biochem. J. (1969) 113, 5-28 (for amendments see item 16 below)].

10. Nomenclature for Vitamins $B_{6}$ and Related Compounds. Tentative Rules [see Biochem. J. (1970) 119, 1-4 (replaces M7 of item 2 above)].

11. Abbreviations and Symbols for Nucleic Acids, Polynucleotides and their Constituents. Recommendations [see Biochem. J. (1970) 120, 449-454 (replaces section 5 of item 1 above)].

12. Abbreviations and Symbols for the Description of the Conformation of Polypeptide Chains. Tentative Rules [see Biochem. J. (1971) 121, 577-585].

13. Tentative Rules for Carbohydrate Nomenclature: Part 1 [see Biochem. J. (1971) 125, 673-695].

14. The Nomenclature of Multiple Forms of Enzymes. Recommendations [see Biochem. J. (1972) 126, 769-771].

15. Symbols for Amino Acid Derivatives and Peptides [see Biochem. J. (1972) 126, 773-780 (supersedes item 3 above)].

16. Amendments to Rules for Nomenclature of Steroids [see Biochem. J. (1972) 127, 613-617 (amendments to item 9 above)].

17. Tentative Rules for the Nomenclature of Carotenoids [see Biochem. J. (1972) 127, 741-752].

18. Abbreviated Nomenclature of Synthetic Polypeptides (Polymerized Amino Acids). Revised Recommendations [see Biochem.J. (1972) 127, 753-756 (supersedes item 6 above)]. 19. Nomenclature of iron-sulphur proteins. Recommendations (this document).

A document, OBN-5, describing the (American) NAS-NRC Office of Biochemical Nomenclature, and listing other rules affecting biochemical nomenclature, is available from its Director, Dr. Waldo E. Cohn [see also J. Chem. Doc. (1967) 7, 72-73; (1969) 9, 235-241]. 